This item was submitted to Loughborough's Research Repository by the author.

Items in Figshare are protected by copyright, with all rights reserved, unless otherwise indicated.

\title{
Size effect in flexural behaviour of unidirectional GFRP composites
}

\section{PLEASE CITE THE PUBLISHED VERSION}

https://doi.org/10.1007/s12206-020-1109-0

\section{PUBLISHER}

Springer Science and Business Media LLC

\section{VERSION}

AM (Accepted Manuscript)

\section{PUBLISHER STATEMENT}

This is a post-peer-review, pre-copyedit version of an article published in Journal of Mechanical Science and Technology. The final authenticated version is available online at: https://doi.org/10.1007/s12206-020-1109-0.

\section{LICENCE}

CC BY-NC-ND 4.0

\section{REPOSITORY RECORD}

Demiral, Murat, Ferhat Kadioglu, and Vadim Silberschmidt. 2020. "Size Effect in Flexural Behaviour of Unidirectional GFRP Composites". Loughborough University. 


\title{
Size effect in flexural behaviour of unidirectional GFRP composites
}

\author{
Murat Demiral $^{1}$, Ferhat Kadioglu ${ }^{2}$ and Vadim V. Silberschmidt ${ }^{3}$ \\ ${ }^{1}$ College of Engineering and Technology, American University of the Middle East, Kuwait, ${ }^{2}$ Ankara Yıldırım Beyazıt University, Ankara 06050, \\ Turkey, ${ }^{3}$ Wolfson School of Mechanical, Electrical and Manu-facturing Engineering, Loughborough University LE11 3TU, UK
}

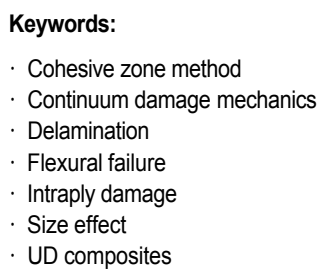

\begin{abstract}
In this paper, the size effect in unidirectional (UD) laminated glass-fibre reinforced plastic (GFRP) composites subjected to quasi-static bending loading was investigated: the sensitivity of a specimen's mechanical behaviour and failure mechanism to its geometry was studied. Composite beams with different numbers of $0^{\circ}$ unidirectional plies were tested and their post-deformation structures were analysed microscopically. In the subsequent simulations, the intraply damage was modelled using continuum damage mechanics, implemented as a user-defined VUMAT subroutine in ABAQUS/Explicit, while cohesive zone elements were employed to characterize the delamination between different plies. It was observed that the flexural failure triggered the multiple delaminations; their location was studied. The influence of the size effect on the bending response of the UD composite beams was analysed in depth. The findings of the current study can be used to design modern structures made of composite materials.
\end{abstract}

\section{Introduction}

Unidirectional (UD) composite materials are used in various applications such as helicopter blades, turbines, compressors, etc. thanks to their higher specific strength and stiffness values. To characterize their mechanical properties such as tensile and compressive strength and to understand their flexural behaviour, bending experiments were performed as this test does not require end tabs to ensure the failure in a gauge area with a reduced cross-section away from the grips. It is also less sever in terms of the effect of geometrical stress concentrations and flaws and does not have any requirement for the cross-sectional shape.

In laminated composite structures subjected to a bending loading, intra-, inter-laminar dam-age, or their combination could occur. The former one occurs due to matrix cracking or plastic-ity, fracture of fibres and debonding at fibre/matrix interface, where the latter develops at a boundary between adjacent plies in the form of debonding, called delamination. The level of strength and the failure mode of a beam subjected to flexural loading depends also on its span-to-thickness ratio $(L / h)$, known as size effect. Some experimental studies in the literature focus on this. For instance, Carbajal and Mujika [1] determined the compressive strength of UD com-posites with different $L / h$ ratios with three-point-bending tests. Westwater [2] observed that the cracks run to a nose of the support in deformed specimens with smaller $L / h$ ratios, while the level of overhang might affect the failure mode. Birger et al. [3] demonstrated that UD compos-ites with an increasing $L / h$ ratio exhibited a shift from shear delamination to yielding of the fibres as the failure mode. Rosensaft and Marom [4] investigated the effects of type and content of fibre on failure behaviour of UD composites. It was observed that in graphite-fibre composites, different from those with glass and Kevlar ones, failure occurred in shear mode rather than tension or compression failure of fibres at lower $L / h$ ratios. Wisnom [5] performed three-point-bending tests of specimens with the same cross-section but different lengths and concluded that the size effect was more sensitive to the specimen length than indicated by Weibull theory. In another study of Wisnom [6], a change in the failure mode from compressive to tensile one 
was found with a decrease in the thickness of UD carbon fibreepoxy specimens. On the other hand, Racz and Vas [7] theoretically investigated the effect of both $L / h$ and width-tothickness ratios on the three-point bending of UD composites. The asymptotic values of the flexural strength, the flexural mod-ulus and shear stress were expressed independently from the $L / h$ values. Moreno et al. [8] determined analytically a relationship between a span and a thickness of a beam to estimate whether the sample failed in a flexural or shear mode in the tests. In that study, different behaviours were accounted for compression and tension of fibres. Liu et al. [9] investigated the interlaminar failure behavior of glass laminate aluminumreinforced epoxy with various $L / h$ ratios subjected to threepoint-bending load. It was shown that the lay-up configuration of glass/epoxy layer strongly affected the failure mode. Mehndiratta et al. [10] found an optimum span length to test flexural strength for the specimens made of carbon and glass prepreg materials. On the other hand, Quang et al. [11] studied the flexural strength of the E-glass/epoxy composite plates subjected to low-velocity loading to observe the characteristics of the delamination. The interlaminar failure behavior of angleplied composites with single lap joints subjected to three point bending tests was studied in Ref. [12]. Study in Ref. [13] analysed the vibration responses of micro composite structures subjected to thermal loading conditions considering the size effect.

Mechanical test of composite samples are usually time consuming and they have to be performed multiple times to account for many parameters. On the other hand, it is difficult to describe the behaviour of laminated composite materials with an analytic model since their failure modes are very complex, with delamination between plies complicating this further [14]. Numerical analyses have been increasingly used to overcome these limitations. For the size effect of UD composites under three-point-bending tests, only a few numerical studies were performed. For instance, Dong and Davies [15] studied the tensile and flexural performances of hybrid composites reinforced with carbon and glass fibres. With an increase in a span-to-depth ratio, the flexural strength grew and a convergence was obtained when this ratio was greater than 32 . Shin et al. [16] investigated the damage behaviour of an aluminiumUD carbon fibre-reinforced polymer (CFRP) composite hybrid beam exposed to three-point-bending. Recently, Tan et al. [17] analysed the role of interfacial properties on intralaminar damage behaviour and delamination of UD composite laminates using a multiscale modelling approach. However, in none of these studies, the size effect of the UD laminates in three-point bending was investigated thoroughly using advanced damage models. For instance, the relationship between different failures such as flexural failure and delamination, the activation of different fracture modes at different positions of a beam and the inertia effects were not addressed in the first place in the context of the size effect. For this purpose, in this study, a mesoscale model was developed. Verification of the threedimensional finite-element (FE) model was carried out with the
Table 1. Dimensions of tested samples.

\begin{tabular}{c|c|c|c|c|c|c}
\hline Material & $I(\mathrm{~mm})$ & $L(\mathrm{~mm})$ & $b(\mathrm{~mm})$ & $h(\mathrm{~mm})$ & \# of lay. & $L / h$ \\
\hline Comp. 1 & 75 & 55 & 20 & 3.800 & 17 & 14.47 \\
\hline Comp. 2 & 90 & 70 & 20 & 2.225 & 10 & 31.46 \\
\hline
\end{tabular}

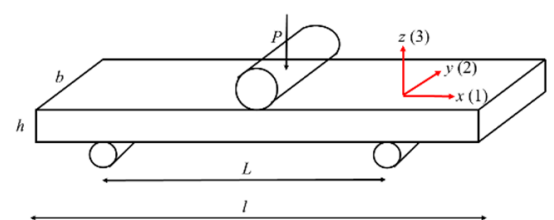

Fig. 1. Sketch of three-point bending test.

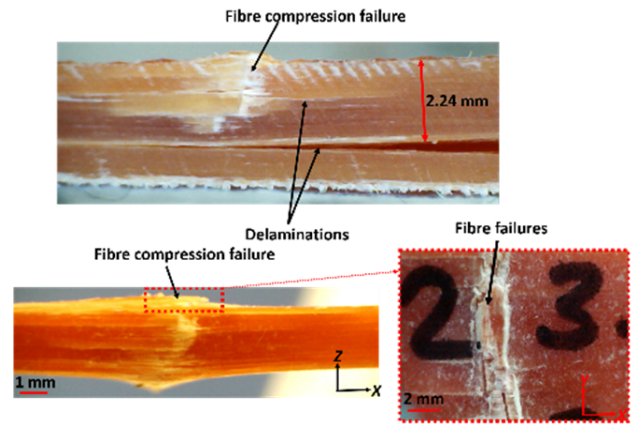

Fig. 2. Post-deformation microscopic images of thicker (top) and thinner (bottom) composite beam.

tests conducted for UD composite beams with different aspect ratios. In simulations, a cohesive-zone model was used to assess the interlaminar damage behaviour. The intralaminar damage was modelled employing continuum damage mechanics based on a composite-failure theory with a threedimensional Hashin and Hou's failure criteria [18], implemented as a user-defined VUMAT subroutine.

\section{Experimental study}

Specimens used in the experiments were manufactured from glass-fibre-reinforced polymer-matrix composite. It is the prepreg of modified epoxy matrix (Hexply 913) and unidirectional glass fibres with volume fractions of $33 \%$ and $67 \%$, respectively. These plates were cured under a pressure of 5 bar for 90 minutes at $130{ }^{\circ} \mathrm{C}$. Afterwards, the bending test samples were obtained by cutting the produced plates to the required dimensions.

The bending tests were performed at room temperature with $50 \%$ relative humidity by using a universal tensile machine (Besmak BMT-S $100 \mathrm{kN}$ ) quasi-statically (with a speed of $2 \mathrm{~mm} / \mathrm{min}$ ) (Fig. 1). Geometrical details of the specimens tested are shown in Table 1. Three identical specimens were prepared for each geometry and tested to check repeatability. Composite 1 consisted of 17 layers, while composite 2 had 10 layers with both having $0^{\circ}$ fibre orientations in each ply. Fig. 2 presents microscopic images of the composite beams after the deformation and damage occurred. The 17-ply specimens 
exhibited flexural failure in the region submitted to compression, and delamination occurred in 2 regions, where the main one was at $2.24 \mathrm{~mm}$ from the top of the beam, while another one was in a plane, where compression failure of fibres was not observed. On the other hand, the 10-plies specimens did not show an apparent delamination, but compression failure of fibres was observed.

\section{Numerical modelling}

This section presents the methodology used in the simulations. Quasi-static analyses of the bending tests were performed using an ABAQUS/Explicit software package [19]. A FE model of the laminated composite material subjected to bending loading is shown in Fig. 3. To simulate the growth of delamination in the form of separation between plies, cohesive interface elements were introduced in the model. The lamina thickness accounting for the resin layer and void content was $0.2 \mathrm{~mm}$. The thickness of cohesive elements was taken as 24 $\mu \mathrm{m}$. The composite plies were modelled using hexahedral continuum linear 8-node solid elements (C3D8R), with distortion control and an enhanced stiffness-based hourglass. Interlaminar damage and inter-face debonding were modelled with linear cohesive $\mathrm{COH} 3 \mathrm{D} 8$ elements. A refined mesh with minimum element sizes of $0.3125 \mathrm{~mm} \times 0.3125 \mathrm{~mm} \times 0.2 \mathrm{~mm}$ and $0.3125 \mathrm{~mm} \times 0.3125 \mathrm{~mm} \times 0.024 \mathrm{~mm}$ was employed for the plies and the interface layers, respectively, in the span region, with a coarser mesh used for the remaining. The stable time increment was defined by the smallest element dimension, i.e., the thickness of cohesive elements. The FE models for composites 1 and 2 contained a total of 278080 and 192128 elements, respectively. Their simulations on the HPC cluster (of 36 CPUs) took around $25 \mathrm{~h}$ and $19 \mathrm{~h}$, respectively.

A general contact algorithm available in ABAQUS with its kinematic constraint-enforcement method for normal behaviour was utilized to model contacts between the punch and the laminate specimen as well as between different composite layers when the cohesive elements were removed from the mesh due to complete damage. The Coulomb friction law was used for tangential motion with a coefficient of $\mu=0.3$ for the punch-composite contact [20,21] and $\mu=0.2$ for the ply-to-ply contacts $[20,22]$. The punch and the tools were modelled with analytical rigid surfaces, where the former was allowed to move only in the z-direction and the latter were fixed with regard to all degrees of freedom to mimic the experiments. In their discretization, a refined mesh with an element size of 0.2 $\mathrm{mm}$ at the interface region was considered.

The continuum damage model and the cohesive-zone method were adopted for the modelling of intra-ply and interply damages, respectively. The fibre failure and matrix damage that could occur within a layer are modelled using continuum damage mechanics with an orthotropic constitutive material model. The VUMAT user subroutine available in ABAQUS Explicit was employed for its implementation [19]. Threedimensional failure criteria based on Hashin and Hou's models
Table 2. Hashin and Hou's 3D failure criteria [17, 18].

\begin{tabular}{c|c|c}
\hline Failure mode & Condition & Failure criteria \\
\hline$f t$ & $\sigma_{11}>0$ & $f_{1}=\left(\frac{\sigma_{11}}{S_{1}^{T}}\right)^{2}+\frac{1}{\left(S_{12}^{F}\right)^{2}}\left(\sigma_{12}^{2}+\sigma_{13}^{2}\right)$ \\
\hline$f C$ & $\sigma_{11}<0$ & $f_{2}=\frac{-\sigma_{11}}{S_{1}^{C}}$ \\
\hline$m t$ & $\sigma_{22}>0$ & $f_{3}=\frac{1}{\left(S_{2}^{T}\right)^{2}}\left(\sigma_{22}\right)^{2}+\frac{1}{\left(S_{23}^{F}\right)^{2}}\left(\sigma_{23}^{2}\right)+\frac{1}{\left(S_{12}^{F}\right)^{2}}\left(\sigma_{12}^{2}\right)$ \\
\hline$m c$ & $\sigma_{22}<0$ & $f_{4}=\frac{1}{4}\left(\frac{-\sigma_{22}}{S_{12}^{F}}\right)^{2}+\frac{\sigma_{22} S_{2}^{C}}{4\left(S_{12}^{F}\right)^{2}}-\frac{\sigma_{22}}{S_{2}^{C}}+\frac{1}{\left(S_{23}^{F}\right)^{2}}\left(\sigma_{12}^{2}\right)$ \\
\hline
\end{tabular}

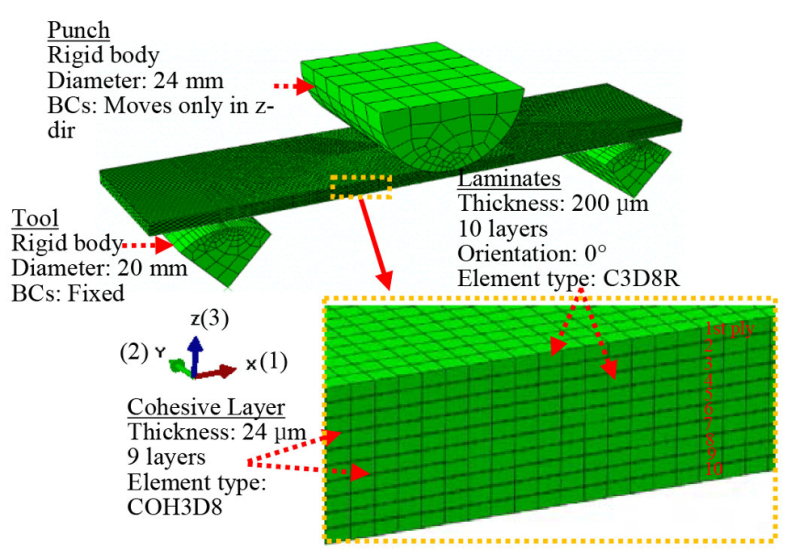

Fig. 3. 3D finite-element model for bending of 10-ply specimens (composite 2).

[18] is adopted for damage initiation.

The model presented in Table 2 includes four different failure modes: (i) fibre tension (ft), (ii) fibre compression (fc), (iii) matrix tension (mt) and (iv) matrix compression (mc). Here, indices 1 and 2 denote in-plane fibre and matrix directions, respectively, and 3 represents the out-of-plane direction. Superscripts $T$ and $C$ denote tension and compression, respectively. $\sigma_{i j}$ and $S_{i j}$ are the stress and strength values, respectively. The particular failure mode was invoked when the corresponding failure indicator $f_{i}(i=1,2,3,4)$ reached 1 . A linear softening response was used to model the dam-age evolution. For each failure mode I, it was defined by the following equation [21]:

$$
d_{I}=\frac{\delta_{I, e q}^{f}\left(\delta_{I, e q}-\delta_{I, e q}^{0}\right)}{\delta_{I, e q}\left(\delta_{I, e q}^{f}-\delta_{I, e q}^{0}\right)} \quad I=f t, f c, m t, m c
$$

where $\delta_{I, e q}^{0}$ and $\delta_{I, e q}^{f}$ are the equivalent displacements at the onset and completion of damage, respectively. $\delta_{I, e q}^{f}$ was obtained using $\delta_{I, e q}^{f}=2 G_{I} / \sigma_{I, e q}$, where $G_{I}$ and $\sigma_{I, e q}$ are the fracture toughness and the equivalent stress for the respective mode. The formulations in Ref. [23] were used to compute the equivalent displacement and stress for each failure mode.

Strains and stresses in a damaged element were related to each other via $\varepsilon=S \sigma$, where $S$ is the compliance matrix defined as [21]: 
Table 3. Properties of composite material used in numerical analyses.

\begin{tabular}{|c|c|c|c|c|c|}
\hline \multicolumn{6}{|c|}{ Elastic (MPa) [24] } \\
\hline$E_{11}$ & $E_{22}=E_{33}$ & $\begin{array}{l}\vartheta_{12,13,23} \\
\text { (no unit) }\end{array}$ & $G_{12}=G_{13}$ & $G_{23}$ & \\
\hline 44000 & 13000 & 0.2736 & 6900 & 6200 & \\
\hline \multicolumn{6}{|c|}{ Strength (MPa) [24] } \\
\hline$\sigma_{1 T}^{u}$ & $\sigma_{1 C}^{u}$ & $\sigma_{2 T}^{u}$ & $\sigma_{2 C}^{u}$ & $\sigma_{12}^{u} \sigma_{13}^{u}$ & $\sigma_{23}^{u}$ \\
\hline 1200 & 850 & 70 & 90 & 95 & 50 \\
\hline \multicolumn{6}{|c|}{ Damage $(\mathrm{N} / \mathrm{mm})$ [25] } \\
\hline$G_{f t}$ & $G_{f c}$ & $G_{m t}$ & $G_{m c}$ & & \\
\hline 100 & 100 & 25 & 25 & & \\
\hline
\end{tabular}

$$
\left[\begin{array}{cccccc}
\frac{1}{E_{11}\left(1-d_{f}\right)} & -\frac{\vartheta_{21}}{E_{22}} & -\frac{\vartheta_{31}}{E_{33}} & 0 & 0 & 0 \\
-\frac{\vartheta_{12}}{E_{11}} & \frac{1}{E_{22}\left(1-d_{m}\right)} & -\frac{\vartheta_{32}}{E_{33}} & 0 & 0 & 0 \\
-\frac{\vartheta_{13}}{E_{11}} & -\frac{\vartheta_{23}}{E_{22}} & \frac{1}{E_{33}\left(1-d_{m}\right)} & 0 & 0 & 0 \\
0 & 0 & 0 & \frac{1}{2 G_{12}\left(1-d_{s}\right)} & 0 & 0 \\
0 & 0 & 0 & 0 & \frac{1}{2 G_{13}\left(1-d_{s}\right)} & 0 \\
0 & 0 & 0 & 0 & 0 & \frac{1}{2 G_{23}\left(1-d_{s}\right)}
\end{array}\right]
$$

where $E_{i j}, \vartheta_{i j}, G_{i j}$ are the elastic constants, $d_{f}$ and $d_{m}$ and $d_{s}$ are are damage variables describing the current states of fibre, matrix and shear damage factors, respectively. Fibre damage is calculated as $d_{f}=1-\left(1-d_{f t}\right) *\left(1-d_{f c}\right)$ and if $\sigma_{22}>0, d_{m}=d_{m t}$, else $d_{m}=d_{m c}$. Shear damage is defined as $d_{s}=1-\left(1-d_{f t}\right) *\left(1-d_{f c}\right) *\left(1-d_{m t}\right) *\left(1-d_{m c}\right)$. Table 3 shows all the material parameters introduced in Abaqus for the simulation of composite plies.

The greatest characteristic in-plane length parameter of an undeformed continuum element, equal to the square root of the product of in-plane element's dimensions, should be smaller than the characteristic length, avoiding a snap-back of a constitutive softening branch, defined as $2 G_{I} E_{I} / \sigma_{I}$ [26], where $I=$ $\mathrm{ft}, \mathrm{fc}, \mathrm{mt}$, mc. This was considered while defining the mesh size of elements used in the modelling of composite plies.

Delamination (interlaminar damage) is one of the dominant failure modes in the composite laminates subjected to flexural loading. To model its onset and growth under the mixed-mode loading conditions, cohesive elements were employed. Details of the model can be found elsewhere [27, 28]. The material parameters presented in Table 4 were used in numerical analyses. Here, $t_{1}^{0}, t_{2}^{0}, t_{3}^{0}$ are the interfacial strengths related to the onset of separation for normal mode, first and second shear modes, respectively. $G_{1 C}, G_{2 C}$ and $G_{3 C}$ are the respective critical energy release rates, $\eta$ is the material modemixity parameter used in the Benzeggagh and Kenane criterion [29] characterizing the damage propagation in this model.

To represent the distribution of tractions in the interface layer
Table 4. Interface properties of glass-fibre-reinforced composite used in numerical analyses [21, 24].

\begin{tabular}{c|c|c|c|c|c}
\hline $\begin{array}{c}E_{0} \\
(\mathrm{MPa} / \mathrm{mm})\end{array}$ & $\begin{array}{c}t_{1}^{0} \\
(\mathrm{MPa})\end{array}$ & $\begin{array}{c}t_{2}^{0}=t_{3}^{0} \\
(\mathrm{MPa})\end{array}$ & $n$ & $\begin{array}{c}G_{1 C} \\
(\mathrm{~N} / \mathrm{mm})\end{array}$ & $\begin{array}{c}G_{2 C}=G_{3 C} \\
(\mathrm{~N} / \mathrm{mm})\end{array}$ \\
\hline $5 \times 10^{5}$ & 50 & 50 & 1.45 & 0.26 & 0.84 \\
\hline
\end{tabular}

appropriately, an adequate number of elements should be used. For interface elements, the cohesive-zone length $l_{C Z}$ was calculated using the formulation proposed by Yang and Cox [30] as $l_{C Z, I}=\left(l_{C H, I}\right)^{1 / 4} h^{3 / 4}$ for mode-l delamination and $l_{C Z, I I}=\sqrt{l_{C H, I I} h}$ for mode-II one. Here, $h$ is the half thickness of the laminate, $l_{C H, i}$ is the characteristic length of the material for failure mode $i=\mathrm{I}$, II equal to $G_{i C} E_{i} / t_{i}$ with $G_{i C}, E_{i}$ and $t_{i}$ being the fracture toughness, elastic modulus and interfacial strength for the corresponding mode, respectively. The respective cohesive zone lengths were $0.8 \mathrm{~mm}$ and $5.79 \mathrm{~mm}$ for modes I and II, respectively; therefore, they were properly split with minimum 2 elements in the simulations.

In the simulations, when the complete damage was attained at all integration points of an element, it was removed from the model.

\section{Result and discussion}

In this section, first force-displacement curves for both composite beams with different span-to-thickness ratios obtained from experiments and FE simulations were compared (Fig. 4). Apparently, a sound agreement of the results was achieved. While the thicker composite could sustain a higher force, the thinner one deflected more, i.e., the former behaved stiffer and the latter more ductile. It is worth mentioning that in the simulations the ratio of kinetic energy to the total energy was kept smaller than $0.5 \%$ to exclude a possible inertia effect on the results. It was computationally impractical to model the process in its natural time period due to a smaller stable time increment in the model with a finer mesh. To avoid this, the simulations were performed for a shorter total time, i.e., less than the experimental one, to benefit in terms of the computational time, with inertia forces being still insignificant. The fluctuations observed in the numerically obtained force-displacement curves in Fig. 4 were due to the low-scale dynamic effects.

A numerically predicted distribution of damages on the composite plies and resin-rich interfaces are demonstrated in Fig. 5. Similar to the experimental observations in Sec. 2, a fibre compression failure and delamination were observed for the thicker composite and a fibre compression failure was observed for the thinner one. Here, the delamination in the second composite did not occur naturally, but was triggered by the failure of elements under compression. As the compressive strength in the fibre direction $(850 \mathrm{MPa})$ was less than the tensile strength (1200 MPa), fibres failed due to compression earlier. A study in Ref. [31] presented that for the $L / h$ ratio greater than $\sigma_{1 C}^{u} / 2 \sigma_{23}^{u}$ 


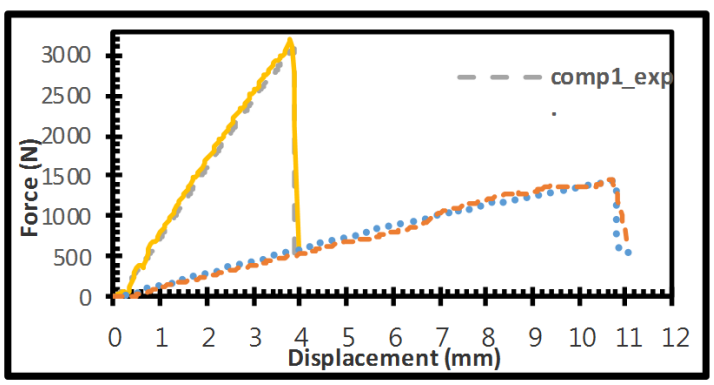

Fig. 4. Experimentally and numerically obtained load displacement curves of the composites 1 and 2 .

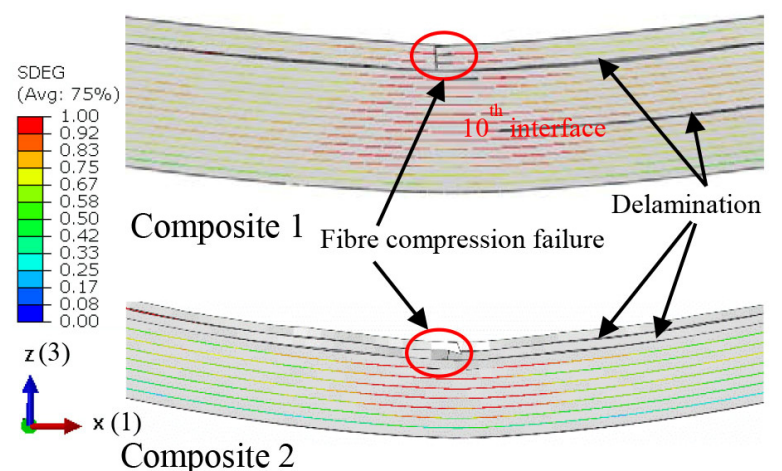

Fig. 5. Numerically obtained schemes of fibre failures and delamination for composites 1 and 2 .

(or $\sigma_{1 C}^{u} / 2 \sigma_{13}^{u}$ ), flexural failure modes such as tension or compression failures of fibres or matrices occurred; otherwise, the shear failure mode such as delamination became prominent. In accord with this, this ratio for composites 1 and $2-14.47$ and 31.46 , respectively - were larger compared to the critical ratio, 4.48 (8.51 for $\sigma_{1 C}^{u} / 2 \sigma_{13}^{u}$ ); hence, the flexural failure modes were mainly active. For the intermediate range of $L / h$ ratios, the behaviour was transitional, i.e., both failure modes occurred simultaneously as deformation progressed. For instance, here, bending of the thicker composite also resulted in the delamination alongside the flexural failure. To summarize, with a decrease in the span-to-thickness ratio, delamination between plies was more likely to occur.

In composite 1, delamination occurred mainly in two resinrich areas, one between the 3rd and 4th plies and another one between the 10th and 11th. They were in agreement with the experimental observations, proving the accuracy of the model qualitatively. The maximum shear stress was obtained at the neutral plane (half of the thickness) of the beams exposed to bending; therefore, the delamination was expected to occur at the respective interfaces of the plies [32]. However, the interlaminar damage was triggered in the upper half of the beam by the fibre compression failure as the shear-stress values at those layers were not large enough to cause the delamination. The interlaminar damage did not occur exactly at the half of the thickness, but below the initial neutral plane. The flexural deformation that happened in the compression region might shift

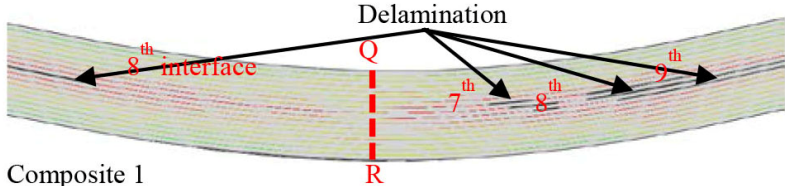

Fig. 6. Delamination pattern for composite 1 obtained for constitutive equations without account for fibre failure. The legend and coordinate systems shown in Fig. 5 applies.

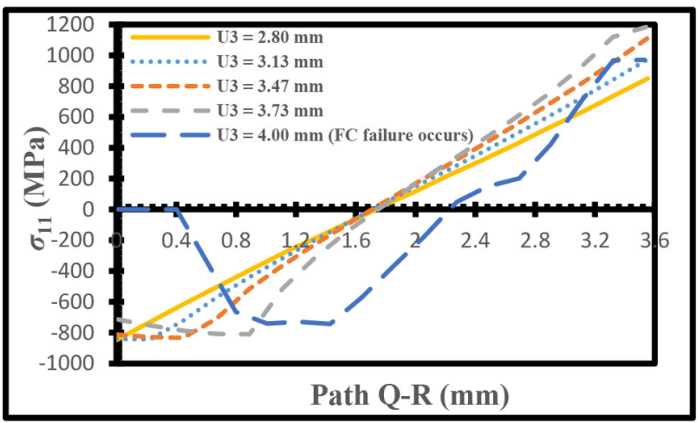

Fig. 7. Distributions of $\sigma_{11}$ along path Q-R (Fig. 6) at different deformation steps for composite 1 .

the location of this delamination. To elucidate this, additional simulations were performed without account for fibre failure in the constitutive equations; Fig. 6 presents the respective failure pattern for composite 1. It was observed that the delaminations occurred mostly at the $7^{\text {th }}, 8^{\text {th }}$ and $9^{\text {th }}$ interfaces, close to the initial neutral plane. This result demonstrated that the failure of fibres in the plies influenced the location of delamination zones.

Fig. 7 depicts the distributions of stress $\sigma_{11}$ along path Q-R (see Fig. 6) in the course of deformation for composite 1, i.e., the punch displaced by $2.80 \mathrm{~mm}, 3.13 \mathrm{~mm}, 3.47 \mathrm{~mm}, 3.73 \mathrm{~mm}$ and $4.00 \mathrm{~mm}$, where, in the last step, the fibre failure just occurred. At the first displacement level, the stress changed linearly between maximum magnitudes of $-850 \mathrm{MPa}$ and $850 \mathrm{MPa}$. This implied that since compressive strength in the fibre direction was $-850 \mathrm{MPa}$, the damage in the upper surface of the composite was initiated. At the second and third levels, while compressive stresses at the points belonging to the upper plies were saturated at $850 \mathrm{MPa}$, the tensile stresses kept increasing since the tensile strength in the fibre direction, $1200 \mathrm{MPa}$, was not reached yet. At the fourth and fifth levels $\left(U_{3}=\right.$ $3.73 \mathrm{~mm}$ and $4 \mathrm{~mm}$ ), as the damage at the upper surface became significant, the respective stress values started to fall, and eventually, the elements were removed upon the complete damage was reached. Whereas, the stress at the lower surface reached their maximum values first, then as a result of damage due to fibre tension, stresses also started to drop there. Interestingly, the neutral plane, defined as a location with $\sigma_{11}=0$, was at the half of the thickness $(1.775 \mathrm{~mm})$ for the first four deformation levels, but when the failure due to fibre compression occurred, the neutral plane shifted by around $0.47 \mathrm{~mm}$ towards the lower surface of the beam, i.e., some $2.25 \mathrm{~mm}$ from the top surface. This region corresponded to the 
$10^{\text {th }}$ interface, where the delamination occurred in the simulations. In fact, this was in good agreement with the place of the delamination in the experiments (Fig. 2, top). The top two composite plies submitted to compression with a total thickness of $0.4 \mathrm{~mm}$ were heavily damaged and ultimately they were deleted. This caused the shift of the neutral plane by a magnitude close to the thickness of failed plies.

The influence of the size effect on the failure modes was investigated by varying the span length in simulations from $70 \mathrm{~mm}$ to $20 \mathrm{~mm}$ while keeping the beam's height constant for composite 2 due to its simplicity in modelling this phenomenon; the respective load-displacement curves are shown in Fig. 8. It was observed that while the maximum load increased, the corresponding displacement value decreased with a decrease in the $L / h$ ratio. Since the decrease in the latter was larger than the increase in the former, the amount of energy absorbed (i.e., the area under the curve) decreased. To get an insight into the deformation responses of composite beams with different $L / h$ ratios, the failure patterns were compared (Figs. 9 and 10). For $L=40 \mathrm{~mm}$, in the course of loading, first, the flexural failure in the region submitted to compression was observed, triggering the delamination between the upper plies of the composite. On the other hand, at the half of the thickness, the flexural failure mode overwhelmed the delamination. Similar observations were done for $L=50 \mathrm{~mm}$ and $60 \mathrm{~mm}$; for the sake of brevity, they were not presented here. However, an opposite case occurred for $L=30 \mathrm{~mm}$, where the delamination mode surpassed the flexural one. But, still, the fibres in the compression region, closer to the contact with the punch, were heavily deformed. On the other hand, when the span decreased further to $20 \mathrm{~mm}$, the delamination occurred only in the fifth cohesive layer, at the half thickness, without any fibre failure (Fig. 10). It was noticed that, although the strength of the composite material in the fibre direction in compression and tension was different, delamination occurred at the midheight of the beam. In a similar case, Moreno et al. [8] observed a non-centred position of the interlaminar opening mode and attributed this to the dissimilar behaviour of the material under compressive and tensile loading. However, the results here demonstrated that the asymmetry of the fibre strength did not necessarily shift the location of delamination from the half thickness, as opposed to the conclusion in Ref. [8].

Analysis of the load-displacement curve for $L / h=20 / 2.225$ demonstrated an abrupt decrease in the load after the maximum value due to interlaminar damage (Fig. 8). However, this was followed by another increase in the load exceeding the first peak's value. Subsequently, another zig-zag was observed; Fig. 10 presents the sequence of delamination initiation and formation. First, the delamination occurred on the left-hand side between the plies at the mid-height. Later, another delamination occurred in the same cohesive layer, but on the other side of the specimen; ultimately, additional delaminations at other interfaces took place. After each delamination in the course of loading, the force dropped. Later, the composite plies started supporting each other thanks to the naturally formed

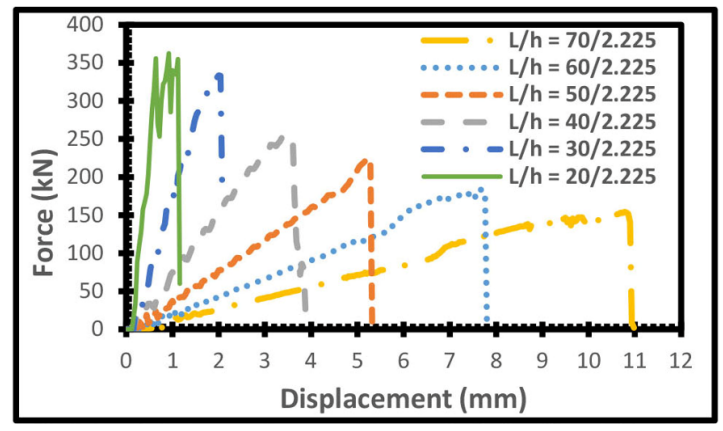

Fig. 8. Load displacement curves of composite 2 with different $L / h$ ratios.

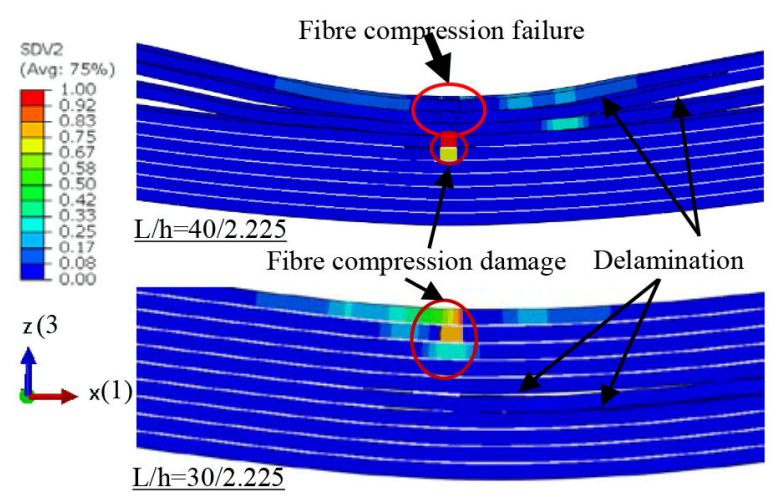

Fig. 9. Failure patterns for composite 2 with different $L / h$ ratios.

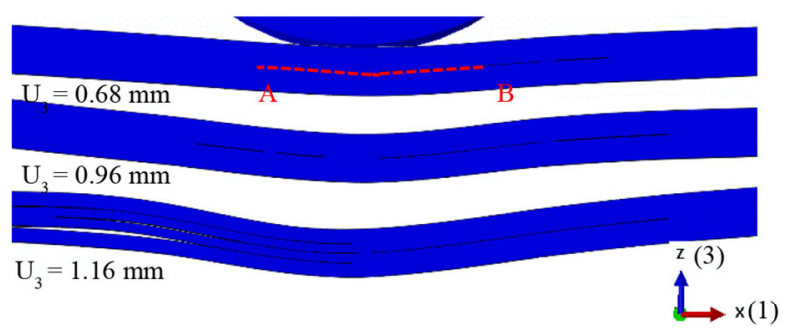

Fig. 10. Initiation and propagation of delamination and resulting failure pattern for composite 2 with $L / h=20 / 2.225$.

contact between the adjacent layers after the cohesive layer disappeared. Consequently, the composite beam could support the increasing load and, hence, the force value exhibited an increasing trend. However, in the beams with larger $L / h$ ratios, while delaminations took place, the fibres also experienced substantial flexural compression failure; hence, they could not sustain the load efficiently.

To compare the contributions of first shear (mode 2) and normal (mode 1) modes to the deformation of resin-rich areas, the respective $\sigma_{13}$ and $\sigma_{33}$ values along path A-B, the cohesive interface layer between $5^{\text {th }}$ and $6^{\text {th }}$ plies (Fig. 10), were plotted (Fig. 11). It was noticed that the values of the second shear mode, mode 3 , was negligible; hence, it is not presented here. Far from the central region, only mode 2 was active, since $\sigma_{33}$ values were close to zero. On the other hand, in the central region ( $3.5 \mathrm{~mm}$ to $5 \mathrm{~mm}$ of the path), while the values of $\sigma_{33}$ became significant, $\sigma_{13}$ changed its sign naturally. 

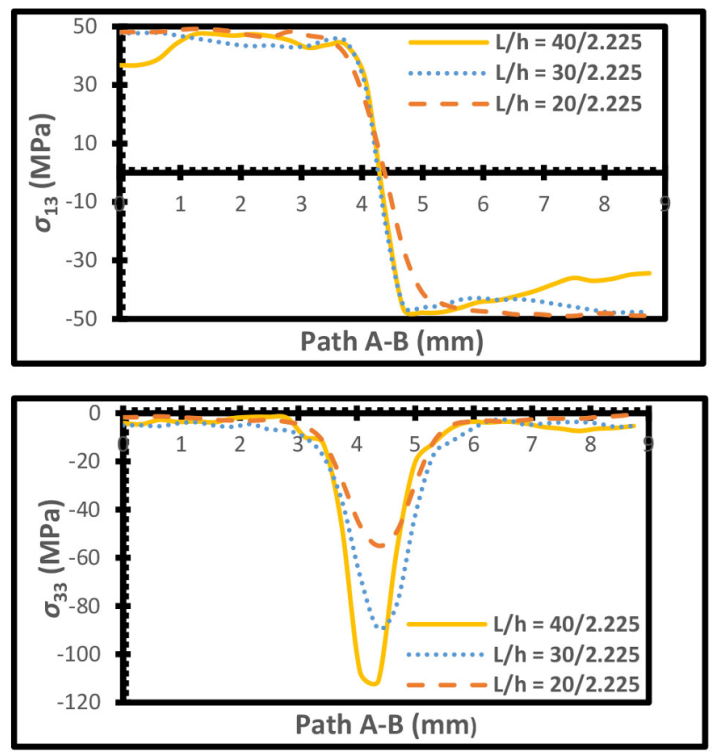

Fig. 11. $\sigma_{13}$ and $\sigma_{33}$ along path $\mathrm{AB}$ (interface between 5 th and 6th plies) (see Fig. 10) for composite 2 with different $L / h$ ratios (just before failure starts)

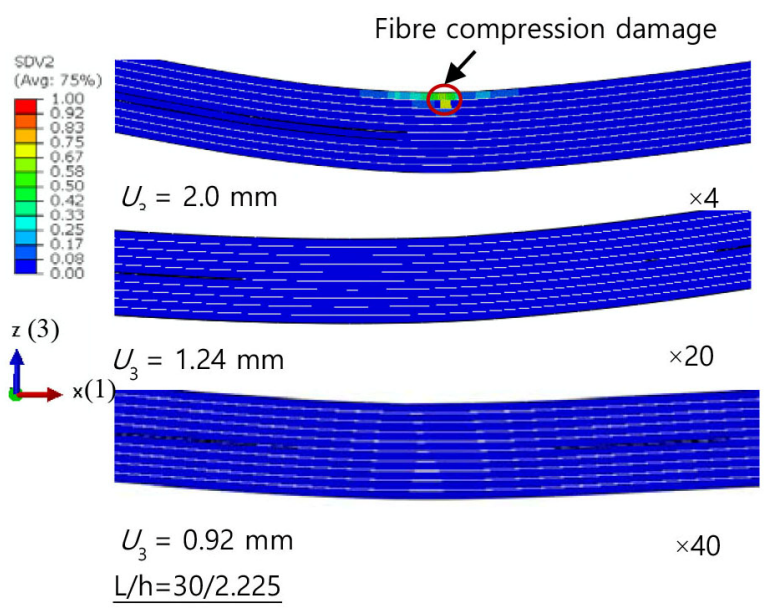

Fig. 12. Failure patterns for composite 2 with different punch speeds $(x 4$, $\times 20, \times 40)$. $\left(U_{3}\right.$ value represents the displacement of the punch for the deformed shape.)

Therefore, mode 1 was considerable in this region. Also, when the span value decreased from $40 \mathrm{~mm}$ to $20 \mathrm{~mm}$, while the $\sigma_{33}$ value decreased, no significant difference in the $\sigma_{13}$ value was observed. So, it can be concluded that the separation of composite layers in the central region due to damage in the cohesive layer occurred less in the opening mode when $L / h$ decreased, i.e., the contribution of the first shear mode became more prominent. This can be explained by the dominance of shear effects in shorter beams.

Generally, composite materials used in advanced engineering applications can be subjected to transverse loading in the form of impact caused by hail storm, tool drops or accidental stepping. To investigate the performance of the composite material studied here under dynamic loading, the speed of the punch was increased by 4, 20 and 40 times in the simulations; Fig. 12 presents the respective failure patterns for $L / h=$ 30/2.225. Taking also the quasi-static one in Fig. 9 into account, it was observed that the damage progress in the fibres due to compression was delayed by inertia effects, and even no fibre failure was observed, while delamination became important when the punch speed increased by 20 and 40 times. Second, the delamination in the composite at first appeared when the punch moved $2.0 \mathrm{~mm}, 1.24 \mathrm{~mm}$ and $0.92 \mathrm{~mm}$ in the negative z-direction with an in-crease in the punch speed from 4 times to 40 times of the quasi-static one, respectively. It was concluded that when the inertia effect became prominent, the delamination of the plies was triggered and occurred earlier, whereas the flexural failure became less probable. A similar observation was done in Ref. [21].

\section{Concluding remarks}

In this article, a numerical approach based on tests was used to study the quasi-static failure behaviour of unidirectional composite laminates under three-point-bending with regard to the size effect. In the simulations, intraply fibre breakage and matrix cracking were modelled using a continuum damage mechanics framework, where the delamination between different plies was accounted for using cohesive-zone elements. From this study, the following conclusions can be drawn:

- Beams, made of composite laminates, with smaller $L / h$ ratio failed due to shear at the neutral axis. At larger $L / h$ ratios, the mode of failure became flexural. In an intermediate range of this ratio, the damage response was transitional, with different failure modes in competition.

- The flexural failure in the composites not only triggered the delamination, but also they affected the location of inter-laminar damage. The influence of the tension-compression asymmetry of the laminates on this was not significant.

- At the neutral axis, the first in-plane shear mode (mode 2) led the interlaminar damage. However, in the central region of the resin-rich area (aligned with the axis of the punch), the opening mode (mode 1 ) became more prominent. With a decrease in the $L / h$ ratio, this effect lessened.

- A transition to dynamic bending with a growing velocity increased the likelihood of occurrence of the interlaminar damage compared to the flexural failure.

\section{References}

[1] N. Carbajal and F. Mujika, Determination of compressive strength of unidirectional composites by three-point bending tests, Polymer Testing, 28 (2) (2009) 150-156.

[2] J. W. Westwater, Flexure testing of plastic materials, Proceedings American Society for Testing and Materials, 49 (1949) 1092-1118.

[3] S. Birger, A. Moshonov and S. Kenig, Failure mechanisms of graphite-fabric epoxy composites subjected to flexural loading, 
Composites, 20 (2) (1989) 136-144.

[4] M. Rosensaft and G. Marom, Evaluation of bending test methods for composite materials, Journal of Composites, Technology and Research, 7 (1) (1985) 12-16.

[5] M. R. Wisnom, Relationship between strength variability and size effect in unidirectional carbon fibre/epoxy, Composites, 22 (1) (1991) 47-52.

[6] M. R. Wisnom, The effect of specimen size on the bending strength of unidirectional carbon fibre-epoxy, Composite Structures, 18 (1) (1991) 47-63.

[7] Z. S. Rácz and L. M. Vas, Relationship between the flexural properties and specimen aspect ratio in unidirectional composites, Composite Interfaces, 12 (3-4) (2005) 325-339.

[8] M. S. Moreno, A. R. Gutiérrez and J. M. Vicente, Different response under tension and compression of unidirectional carbon fibre laminates in a three-point bending test, Composite Structures, 136 (2016) 706-711.

[9] C. Liu, D. Du, H. Li, Y. Hu, Y. Xu, J. Tian and J. Tao, Interlaminar failure behavior of GLARE laminates under short-beam three-point-bending load, Composites Part B: Engineering, 97 (2016) 361-367.

[10] A. Mehndiratta, S. Bandyopadhyaya, V. Kumar and D. Kumar, Experimental investigation of span length for flexural test of fiber reinforced polymer composite laminates, Journal of Materials Research and Technology, 7 (1) (2018) 89-95.

[11] P. X. Quang, S. Wicaksono, T. Dirgantara and B. K. Hadi, The effect of low-velocity impact on the flexural strength of Eglass/epoxy composite plates, Journal of Mechanical Science and Technology, 34 (2020) 1879-1886.

[12] F. Kadioglu and M. Demiral, Failure behaviour of the single lap joints of angle-plied composites under three point bending tests, Journal of Adhesion Science and Technology, 34 (5) (2020) 531-548.

[13] A. Saeed, Z. Soleimani-Javid and E. Arshid, Size - dependent free vibration of sandwich micro beam with porous core subjected to thermal load based on SSDBT, Journal of Applied Mathematics and Mechanics, 99 (9) (2019) e201800334.

[14] X. Qin, B. Wang, G. Wang, H. Li, Y. Jiang and X. Zhang, Delamination analysis of the helical milling of carbon fiberreinforced plastics by using the artificial neural network model, Journal of Mechanical Science and Technology, 28 (2) (2014) 713719.

[15] C. Dong and I. J. Davies, Flexural and tensile strengths of unidirectional hybrid epoxy composites reinforced by S-2 glass and T700S carbon fibres, Materials and Design (1980-2015), 54 (2014) 955-966.

[16] D. K. Shin, H. C. Kim and J. J. Lee, Numerical analysis of the damage behavior of an aluminum/CFRP hybrid beam under three point bending, Composite Part B, 56 (2014) 397-407.

[17] W. Tan, F. Naya, L. Yang, T. Chang, B. G. Falzon, L. Zhan, J. M. Molina-Aldareguía, C. González and J. Llorca, The role of interfacial properties on the intralaminar and interlaminar damage behaviour of unidirectional composite laminates: experimental characterization and multiscale modelling, Composites
Part B, 138 (2018) 206-221

[18] J. P. Hou, N. Petrinic, C. Ruiz and S. R. Hallett, Prediction of impact damage in composite plates, Composite Science and Technology, 60 (2) (2000) 273-281.

[19] ABAQUS 6.13 User's Manual, Dassault Systems, Providence, $\mathrm{RI}(2013)$.

[20] J. Schön, Coefficient of friction of composite delamination surfaces, Wear, 237 (1) (2000) 77-89.

[21] O. T. Topac, B. Gozluklu, E. Gurses and D. Coker, Experimental and computational study of the damage process in CFRP composite beams under low-velocity impact, Composite Part A, 92 (2017) 167-82.

[22] C. S. Lopes, P. P. Camanho, Z. Gürdal, P. Maimí and E. V. González, Low-velocity impact damage on dispersed stacking sequence laminates, part II: numerical simulations, Composite Science and Technology, 69 (7-8) (2009) 937-947.

[23] C. Zhang, N. Li, W. Wang, W. K. Binienda and H. Fang, Progressive damage simulation of triaxially braided composite using a 3D meso-scale finite element model, Composite Structures, 125 (2015) 104-116.

[24] M. Demiral and F. Kadioglu, Failure behaviour of the adhesive layer and angle ply composite adherends in single lap joints: a numerical study, International Journal of Adhesion and Adhesives, 87 (2018) 181-190.

[25] N. O. Yokoyama, M. V. Donadon and S. F. De Almeida, A numerical study on the impact resistance of composite shells using an energy based failure model, Composite Structures, 93 (1) (2010) 142-152.

[26] E. V. González, P. Maimí, P. P. Camanho, A. Turon and J. A. Mayugo, Simulation of drop-weight impact and compression after impact tests on composite laminates, Composite Structures, 94 (11) (2012) 3364-3378.

[27] K, Woo, Fracture analysis of woven textile composite using cohesive zone modeling, Journal of Mechanical Science and Technology, 31 (4) (2017) 1629-1637.

[28] R. F. Swati, L. H. Wen, H. Elahi, A. A. Khan and S. Shad, Experimental and numerical investigation of transversal damage in carbon fiber reinforced composites using X-FEM analysis, Journal of Mechanical Science and Technology, 33 (1) (2019) 205-211.

[29] M. L. Benzeggagh and M. Kenane, Measurement of mixedmode delamination fracture toughness of unidirectional glass/epoxy composites with mixed-mode bending apparatus, Composite Science and Technology, 56 (4) (1996) 439-449.

[30] Q. Yang and B. Cox, Cohesive models for damage evolution in laminated composites, International Journal of Fracture, 133 (2) (2005) 107-137.

[31] E. Sideridis and G. A. Papadopoulos, Short-beam and threepoint - bending tests for the study of shear and flexural properties in unidirectional-fiber-reinforced epoxy composites, Journal of Applied Polymer Science, 93 (1) (2004) 63-74.

[32] M. Demiral, H. Tanabi and B. Sabuncuoglu, Experimental and numerical investigation of transverse shear behavior of glassfibre composites with embedded vascular channel, Composite Structures (2020) 12697. 